ISSN: 2224-0616

Int. J . Agril. Res. Innov. \& Tech. 2 (2): 25-35, December, 2012 Available online at http://www.ijarit.webs.com

\title{
STUDY ON BIOFORTIFICATION OF RICE BY TARGETED GENETIC ENGINEERING
}

\author{
Sumon M. Hossain* and A.K.M. Mohiuddin
}

Received 6 October 2012, Revised 10 December 2012, Accepted 25 December 2012, Published online 31 December 2012

\begin{abstract}
Micronutrient malnutrition is a major health problem in Bangladesh and also in many other developing countries, where a diversified diet is not affordable for the majority. In the present world- one, out of seven people suffers from hunger. Yet, there is a stealthier form of hunger than lack of food: micronutrient malnutrition or hidden hunger. While often providing enough calories, monotonous diets (of rural poor) frequently fail to deliver sufficient quantities of essential minerals and vitamins. Due to micronutrient deficiencies different characteristic features have been observed to the victims. Various estimates indicate that over two-thirds of the world population, for the most part women and children specially, pre-school children are deficient in at least one micronutrient. This can have devastating consequences for the life, health and well being of the individuals concerned (like premature death, blindness, weakened immune systems etc). Genetic engineering approach is the upcoming strategy to solve this problem. Genetically engineered biofortified staple crops specially, rice that are high in essential micronutrients ( $\mathrm{Fe}, \mathrm{Zn}$, vitamin $\mathrm{A}$ ) and adapted to local growing environments have the potential to significantly reduce the prevalence of micronutrient deficiencies specially to the rural poor.
\end{abstract}

Keywords: Malnutrition, Biofortification, Rural Health, Genetic Engineering, Iron, Zinc, Vitamin A

Department of Biotechnology and Genetic Engineering, Mawlana Bhashani Science and Technology University Tangail-1902, Bangladesh

*Corresponding author's email: sumonmeister@gmail.com (Sumon M. Hossain)

\section{Introduction}

Globally, malnutrition is a matter of concern and erratically increase day by day, which including both overt nutrient deficiencies as well as dietrelated chronic diseases (e.g., heart disease, cancer, stroke and diabetes) and is responsible for world huge population deaths than any other cause addressing for over 20 million mortalities annually (Kennedy et al., 2003; WHO and FAO, 2003). Malnutrition also contributes to increase morbidity, disability, stunt mental and physical growth and reduce national socio-economic development (WHO and FAO, 2003). Micronutrient malnutrition are mainly affected over two billion people mostly among resourcepoor families in developing countries like Bangladesh with iron, iodine, zinc and vitamin-A deficiencies most prevalent (Kennedy et al., 2003). Over five millions pre-school children deaths occur due to the micronutrient malnutrition every year (Anonymous, 2007). World leading global economists have identified investing in strategies to reduce micronutrient malnutrition as the most cost effective manner (Anonymous, 2008).
Micronutrients are nutrients required by humans and other living things throughout life in small quantities to orchestrate a whole range of physiological functions, but which the organism itself cannot produce and body meet this valuable nutrient from diet.

Dysfunctional food systems that cannot supply all the nutrients and health promoting factors that are required for human life in sustainable ways. However, food systems that feed the disadvantaged are very complex (Sobal et al., 1998). Therefore, dysfunctions in numerous interacting factors can result in inadequate supplies of nutrients reaching the most vulnerable populations (World Bank, 2007). Importantly, because food systems are dependent on agricultural products as their source of most nutrients, agricultural systems must be contributing to this worldwide quandary in public health (Welch, 2001). Unfortunately, agricultural systems have never been explicitly designed to promote human health mostly focusing on increased profitability for farmers and agricultural industries. Agriculture meets the challenge of feeding the world's poor during the "Green Revolution" focusing primarily on three staple crops - rice, wheat and maize. These 
crops provided enough energy to prevent widespread famines in many developing nations like Bangladesh. An unforeseen consequence of that agricultural revolution was the rapid rise in micronutrient malnutrition in many developing nations that adopted the cropping systems that prevented large scale starvations as well as malnutritional diseases (Welch and Graham, 1999).

Ten leading causes of illness and diseases in low income developing countries (Table 1).

Table 1. Ten leading cause of illness and diseases in low income developing countries (WHO, 2002)

\begin{tabular}{lc}
\hline Risk Factors & Ratio (\%) \\
\hline Under Weight & 14.9 \\
Unsafe Sex & 10.2
\end{tabular}

Unsafe Water

Indoor Smoke

3.7

Zinc Deficiency

3.2

Iron Deficiency

3.1

Vitamin A Deficiency (VAD)

3.0

Blood Pressure

Tobacco

Cholesterol

1.9

Here we see that deficiency of Iron, Zinc and Vitamin A are the leading cause of illness and death in the low income developing countries.

Mentioned before that, several strategies are pursued to defeat micronutrient malnutrition worldwide, notably the nutritional enhancement of rice and other cereals through fortification, traditional or conventional breeding and genetic engineering (Fig. 1).

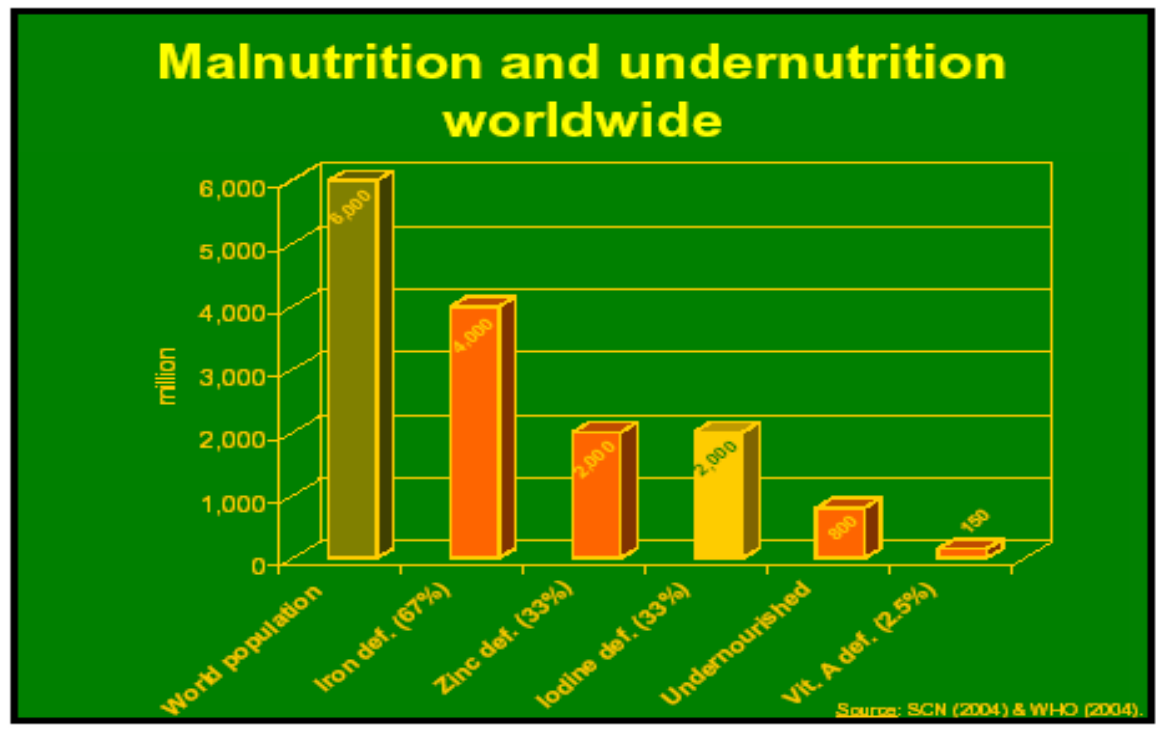

Fig. 1. Malnutrition and under nutrition worldwide [Source: UN/SCN (2004) and WHO (2004)]

Biofortification (developing food crops that fortify themselves) is a method of increasing nutritional value by adding the essential minerals and vitamins, is the first agricultural tool now being employed to address micronutrient malnutrition worldwide.

According to International Center for Tropical Agriculture, (CIAT/IFPRI, 2002) "The goal of the proposed program is to improve the health of poor people by breeding staple food (Rice) crops that are rich in micronutrients, a process referred to here as "biofortification."

According to Sally Brooks, "Bio-fortification is the enrichment of staple food crops with essential micronutrients. Considerable attention and resources are being directed towards the biofortification of rice- the world's most important food crop."
Rice is the predominant staple food in at least 35 countries in the world, where micronutrient malnutrition is widely spread in the developing countries among them. Rice endosperms are the most important source of human food and which can provide as much as $80-85 \%$ in the daily calorie intake to the 2.5-3.0 billion people, half of the world's populations (Meng et al., 2005)

Biofortification of rice is a method of increasing nutritional value by adding the essential minerals and vitamins into the rice endosperm. This can be done either through conventional selective breeding, or through genetic engineering. Biofortification of rice differs from ordinary fortification because it focuses on making rice foods more nutritious as the rice plants are growing, rather than having nutrients added to the rice foods when they are being processed. This is an improvement on 
ordinary fortification when it comes to providing nutrients for the rural poor, who rarely have access to commercially fortified foods. As such, biofortification of rice is seen as an upcoming strategy for dealing with deficiencies of micronutrients in the developing world. In Bangladesh it has been rarely seen in the rural primary school where the government freely supplies fortified biscuits to the pre-school children to meet the essential nutrients.

Genetic engineering, or rDNA (ribosomal DNA), is a technique that offers still greater speed and reach because it moves specific genes with desired traits from a source organism one which does not have to be a related organism directly into the living DNA of a target organism. The transgenic trait is added without normal biological reproduction, but once in the plant it becomes inheritable through normal reproduction. Scientists first developed this technique in the laboratory in 1973 and have been using it to transform agricultural crop plants since the 1980s. Once a useful gene has been identified (which can require a major research project and many years), it is attached to both marker and promoter genes and then inserted into a plant, usually using a non-viable virus called Agrobacterium as a carrier. GE produces plants that are known as transgenic, or less precisely as GMOs.

This review will focus on genetic engineering approaches to improve nutritional quality of rice: increasing the amount of bioavailable iron, zinc and introducing the $\beta$-carotene biosynthetic pathway in the rice endosperm, Because conventional breeding approach has some limitations: it is a long term process requiring variety of breeding activities and huge resources. In addition, it is uncertain whether this strategy will effectively work after all the long-term efforts. The breeding steps include at least (1) identification of a useful genetic variation and the most promising parents, (2) long-term crossing and back-crossing activities, (3) stability of the target traits (e.g. high grain $\mathrm{Fe}, \mathrm{Zn}$ concentrations) across the different environments that feature huge variation in soil and climatic conditions, and finally (4) adaptation of the newly developed biofortified genotypes over a range of crop and soil management practices applied in the target regions or countries. The acceptance of biofortified crops by producers is a further issue that needs a special attention. Most importantly, newly developed genotypes should be able to extract sufficiently large amounts of $\mathrm{Fe}, \mathrm{Zn}$ from potentially $\mathrm{Fe}, \mathrm{Zn}$-deficient soils and accumulate it in whole grain at sufficient levels for human nutrition.

\section{Overview of the proposal}

A new paradigm for agriculture in the 21st century was proposed (Welch and Graham, 2000) that views agriculture as an instrument for public health and focuses attention on the role of agriculture in delivering nutrients to humans and animals in balanced amounts that can sustain maximal physical and mental activity of the humans who are simultaneously the drivers of the food system and its dependents. This is known as the productive, sustainable, and nutritious food systems paradigm for agriculture and public health.

"It is time that IRRI lets go of the illusion that genetic engineering is an upcoming tool that would be benefited farmers and humankind. IRRI should start focusing its attention and resources on tools that would actually work to ensure that rice developers, growers and consumers have access to non-GE rice that is free of corporate control," said Daniel M. Ocampo, Sustainable Agriculture Campaigner of Greenpeace Southeast Asia.

\section{Rationale and significance}

The biofortification of rice strategy seeks to take advantage of the consistent daily consumption of large amounts of rice by all family members in Bangladesh (because rice is our staple food), including women and children who are most at risk for micronutrient malnutrition. As a consequence of the predominance of rice staples in the diets of the poor people, this strategy implicitly targets low-income households. After the one-time investment is made to develop seeds that fortify themselves, recurrent costs are low and germplasm may be shared internationally (conventional breeding). It is this multiplier aspect of plant breeding across time and distance that makes it so cost-effective. Once in place, the biofortified rice crop system is highly sustainable. Nutritionally improved varieties will continue to be grown and consumed year after year, even if government attention and international funding for micronutrient issues fades.

Table 2. Global mortality in children under 5 years of age in 2004 (Source: Black et al., 2008)

\begin{tabular}{ll}
\hline Micronutrient Deficiency & Deaths \\
\hline Vitamin A & $6,66,771$ \\
Zinc & $4,53,207$ \\
Iron & 20,854 \\
Iodine & 3,619 \\
\hline
\end{tabular}

From the above chart, Vitamin A deficiency (VAD) is a serious form of malnutrition to the children that weakens the immune system and may cause blindness. Several measures address 
VAD and have shown positive results. Genetically modified rice containing beta-carotene is a new approach in an early experimental stage.

Biofortification of rice provides a truly feasible means of reaching malnourished populations in relatively remote rural areas, delivering naturally fortified rice to people with limited access commercially-marketed fortified rice, which are more readily available in urban areas. Biofortification and commercial fortification of rice, therefore, are highly complementary.

The ultimate goal of biofortification of rice strategy is to reduce mortality and morbidity rates related to micronutrient malnutrition and to increase food security, productivity, and the quality of life for poor populations of developing countries like Bangladesh where $40 \%$ people living under poverty (http://www. indexmundi. com) because of, there poverty most of them are eaten only two times in a day. So, they need more and more nutrients to meet the normal physical activity as well as for leading their healthy life especially for the pre-school children. After all it is the ongoing process that children are the future asset of a country.

\section{Biotechnology Vs Biofortification}

Biofortification capitalizes on the consistent daily intake of food staples, thus indirectly targeting low-income households who cannot afford a more diverse diet especially for the rural poor. After the initial investment of developing fortified staple crops, no extra costs are needed, and also making this strategy very sustainable and beneficiary. Furthermore, the genetically improved varieties can be shared internationally. The rice endosperms should be biofortified specially that rice variety, whose has huge yield in local territory because targeting for biofortification of rice is not for high yielding but also improved the rice quality especially for micronutrients. Biofortified rice endosperms are also likely to have an indirect impact in agriculture and environment, as a higher trace mineral content in seeds that confer better protection against pests, herbicides, diseases, and environmental stresses (like PH, temperature etc ), thereby increasing yield (Welch and Graham, 2004). Biofortification is not a panacea in itself but a very important complement to dietary variety and to supplementation.

Biofortified rice can be developed by genetic engineering or conventional breeding methods, provided there is sufficient genetic variation in crop populations for the desired trait (such as high protein content). In staple grains such as rice, improvement of some complex traits such as vitamin $\mathrm{A}$ is not possible using conventional breeding strategies, as there are no natural rice varieties rich in this vitamin. All plants produce pro-vitamin A, but only in the green organs of the plant and not in the starch-storing part of the seed. Conventional breeding is also very difficult in vegetatively propagated varieties (such as cassava and potatoes), due to the scarcity of genetically well-defined breeding lines (Welch and Graham, 2004). In addition, conventional breeding can change important traits of the crops desired by consumers, such as taste. Agricultural biotechnology methods, and in specific genetic engineering (GM), represent therefore a very valuable, complementary strategy for the development of more nutritious rice.

\section{Micronutrient deficiency and its impact}

A prerequisite for rural health is a diversified diet with sufficient micronutrients. These micronutrients include trace minerals and vitamins. Iron deficiency anaemia and vitamin A deficiency blindness are two major forms of disorders caused by micronutrient malnutrition (FAO, 1997).

Anaemia which caused by deficiency of Iron is far the most common micronutrient deficiency worldwide. It is also highly prevalent in developed countries both in women of childbearing ages (Milman and Kirchhoff, 1992) and in children (Dallman et al., 1980). Severe anaemia in pregnant women is estimated to be responsible for up to $42 \%$ of the half a million deaths associated with childbirth each year (Seymour and Klein, 1996).

Vitamin A deficiency affects about 30 countries (FAO, 1997), including some 16 million children in the developing world. The early stages of vitamin A deficiency are characterized by impaired dark adaptation, which will progress, if uncorrected, to nyctalopia (night blindness), xerophthalmia and total blindness. In Southeast Asia, it is estimated that a quarter of a million children go blind each year because of vitamin A deficiency (Sommer, 1988).

The importance of micronutrient deficiencies is well known and documented (Table 3). According to the World Health Organization (WHO), "More than 2.0-2.5 billion people in the world today are estimated to be deficient in key vitamins and minerals, particularly vitamin A, iodine, iron and zinc. Most of these people live in low income countries and are typically deficient in more than one micronutrient" (WHO, World Food Programme, \& UNICEF, 2007). 
Table 3. Micronutrient deficiencies and their estimated impacts

\begin{tabular}{|c|c|}
\hline Iron & $\begin{array}{l}\text { Highest risk of iron deficiency occurs during rapid growth and nutritional demand, } \\
\text { such as in children, adolescence and pregnancy. Also associated with maternal } \\
\text { death, impaired physical and cognitive development, increased risk of morbidity in } \\
\text { children, and reduced work productivity in adults. Can be addressed through } \\
\text { fortification of wheat products. WHO estimates } 2 \text { billion people are anemic, and this } \\
\text { is frequently exacerbated by infectious diseases. Malaria, HIV/ AIDS, hookworm } \\
\text { infestation, schistosomiasis, and tuberculosis contribute to a high prevalence of } \\
\text { anemia in some areas. Efforts to increase iron intake must be accompanied by } \\
\text { efforts to control infectious disease. }\end{array}$ \\
\hline Zinc & $\begin{array}{l}\text { Associated with reduced immune status in neonates and children. Preliminary } \\
\text { research shows that additional zinc can reduce incidence of diarrhea and pneumonia } \\
\text { in children and improves maternal health. One estimate shows zinc as close to iron } \\
\text { deficiency in contribution to the global burden of disease. Can be provided through } \\
\text { supplements. }\end{array}$ \\
\hline Vitamin A & $\begin{array}{l}\text { Associated with reduced immune system functioning and a higher incidence of } \\
\text { illness and complications from illness and also associated with blindness and } \\
\text { increased risk of disease and death for small children and pregnant women. Can be } \\
\text { addressed through supplements, which are now estimated to reach children at least } \\
\text { once a year in } 40 \text { countries. The UN Standing Committee on Nutrition (UN/SCN) } \\
\text { estimates that } 140 \text { million children and } 7 \text { million pregnant women are VA deficient, } \\
\text { primarily in Africa and South/Southeast Asia. In 1998, WHO, UNICEF, Canadian } \\
\text { International Development Agency, USAID, and the Micronutrient Initiative } \\
\text { launched the VA Global Initiative. This provides support to countries in delivering } \\
\text { VA supplements. }\end{array}$ \\
\hline Iodine & $\begin{array}{l}\text { Associated with brain damage. Easily mitigated with iodized salt. While incidence } \\
\text { has declined dramatically in recent years due to the universal adoption of salt } \\
\text { iodization starting in 1993, WHO estimates that } 54 \text { countries still have some iodine } \\
\text { deficiency. }\end{array}$ \\
\hline Folate & $\begin{array}{l}\text { Deficiency results in serious disorders, including neural tube defects (NTD) such } \\
\text { as spina bifida in infants, with an estimated } 2,00,000 \text { severe birth defects every } \\
\text { year and megaloblastic anemia. Adequate dietary folate intake can prevent onset of } \\
\text { these conditions. Deficiency also associated with increased risk of maternal death } \\
\text { and complications in birth; can be addressed through fortification of wheat } \\
\text { products. }\end{array}$ \\
\hline
\end{tabular}

From the Table 3, deficiencies of iodine, vitamin $\mathrm{A}$, and iron are the most prevalent for global public health in terms of numbers of individuals in a position to secure large benefits; folate and zinc have important but more limited or less understood impacts in the body. The World Bank estimates that $\$ 180$ billion in lost productivity globally could be prevented with only $\$ 4$ to $\$ 5$ billion invested in deficiency prevention, using currently available technologies (Behrman et al., 2004). It is now recognized that micronutrient deficiencies are persistent public health problems that require direct intervention during the process of economic development.

\section{Iron and Zinc biofortificaion}

Iron $(\mathrm{Fe})$ and zinc ( $\mathrm{Zn})$ are essential micronutrients in both plant and animal kingdom. Amplification of the natural iron stores is a further strategy to increase iron accumulation in the rice endosperms. Both plants and animals use ferritin (organic form) as the form of iron storage during developmental stage. Plant ferritin is composed of 24 subunits (Lobreaux et al., 1992), which together can store up to 4000 iron atoms in the central cavity of the ferritin complex. A recent revaluation demonstrated that ferritin as a good bioavailable iron source (Murray-Kolb et al., 2003).

Now-a-days many reports investigated the possibility of accumulating iron in plants by ferritin gene transformation strategies. Several methods are being used for gene transformation, such as:

\section{$\checkmark$ Agrobacterium mediated gene transfer \\ $\checkmark$ Chemically mediated gene transfer \\ $\checkmark$ Electroporation \\ $\checkmark$ Microinjection \\ $\checkmark$ Microprojectile bombardment method}

The well developed strategies is the Agrobacterium-mediated gene transfer among all others gene transformation method, because Agrobacterium tumefaciens is a soil born 
natural genetic engineer. The transformation of dicotyledons by Agrobacterium is well established. However, transformation methods based on the use of Agrobacterium are still preferred in many instances because of the following properties:

$\begin{array}{ll}\checkmark & \text { Easy to handle } \\ \checkmark & \text { Higher efficiency } \\ \checkmark & \text { More predictable } \\ \checkmark & \text { Pattern of foreign DNA integration, and } \\ \checkmark & \text { Low copy number of integration. }\end{array}$

This vector was the discovery that the T-DNA and the Vir region could be separated onto two different plasmids.

For Example, Transgenic tobacco plants with a high iron-content have been produced via Agrobacterium-mediated gene transfer of the soybean ferritin cDNA under control of a CaMV 35S promoter (Goto et al., 1998).

Goto and his colleagues (1998) reported an outstanding correlation between ferritin levels and iron aocumulation in ferritin-transformed tobacco leaves, raising the possibility that higher iron concentration could be achieved by increasing ferritin expression. In rice, the same ferritin gene expression, driven by a constitutive promoter, led to an increase in iron content of the vegetative parts of rice but not in the seeds (Drakakaki et al., 2000). Goto et al. (2000) reported that transgenic lettuce, constitutively expressing ferritin, grew larger and faster than the control. Moreover, he reported the endospermspecific expression of soybean ferritin in rice seeds with maximum three-fold increase in one of the transformants (Goto et al., 1999).

Recently, an extremely high expression of soybean ferritin driven by the rice glutelin promoter was reported in rice endosperm (Qu et al., 2005), with levels of the transgenic protein up to 13-fold higher than previously reported (Goto et al., 1999). Unfortunately, the maximum iron concentration in the seeds of the new lines was only about $30 \%$ higher compared with previously transformants and about three-fold higher than in the non-transformed control seeds. The authors (Qu et al., 2005) observed that the mean iron concentration in leaves of high ferritin expressing lines decreased to less than half of the nontransformed plants, and the plants showed chlorosis after flowering, even on iron-rich medium. Qu and collaborators concluded that accumulation of iron in the seeds of hyperexpression ferritin rice did not only depend on the expression level of exogenous ferritin but may also be limited by Fe uptake and transport.

\section{Two plant genes help to mobilize and} store Iron and Zinc in rice

Recently succeeded in increasing the iron content in polished rice by transferring two plant genes into an existing japonica rice variety.

$>$ One gene encodes nicotianamine synthase, the enzyme that produces nicotianamine. Nicotianamine chelates iron temporarily and facilitates its transport in the rice plant. Nicotianamine synthase is expressed under a constitutive promoter

$>$ Second gene encodes the protein ferritin, which functions as a storage depot for up to four thousand iron atoms per protein molecule in both plants and humans. Since the ferritin gene is expressed under the control of a specific promoter.

$>$ These two genes allow the rice plant to absorb more iron from the soil, transport it in the plant, and store it in the rice kernel.

$>$ A third gene encoding phytase was also engineered into this rice line. Phytase degrades phytate which can store phosphate and bind divalent cations like iron and thus inhibits their absorption in the intestine.

> The pmi (Escherichia coli phosphomannoseisomerase) gene was used as a selectable marker

$>$ starting material and gene transfer is mediated by Agrobacterium tumefaciens strain LBA4404

> Primary transformants is obtained after transformation and selection on mannose.

> Plants were regenerated and analysed by Southern blot.

> The genetically engineered lines expressing nicotianamine synthase, ferritin, and phytase (NFP-line) contain up to a 6.3-fold increase of iron in the endosperm of polished kernels.

$>$ Overexpression of the NAS gene in rice would enhance the synthesis of NA (Nicotinamine) and DMA (2'-deoxymugineic acid), and thus increase $\mathrm{Fe}$ and $\mathrm{Zn}$ concentrations in seeds.

Higuchi et al. (2001) introduced the HvNAS1 gene into rice under the control of the 35S promoter. The resultant transgenic lines produced two to threefold greater concentrations of NA compared to non-transgenic lines. DMA production and secretion also increased under Fe-sufficient conditions. Laser ablation inductive coupled plasma mass spectroscopy (LA-ICP-MS) confirmed the accumulation of additional iron in the endosperm of NFP lines by imaging micro-Xray fluorescence spectroscopy. 


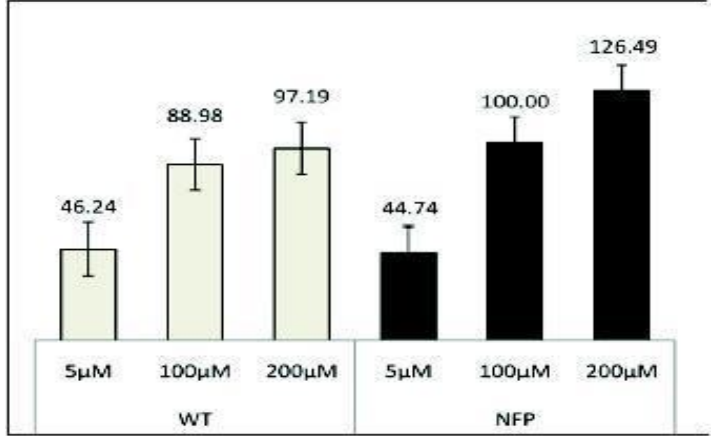

Fig. 2. Iron concentration in leaves (WT vs NEP line)

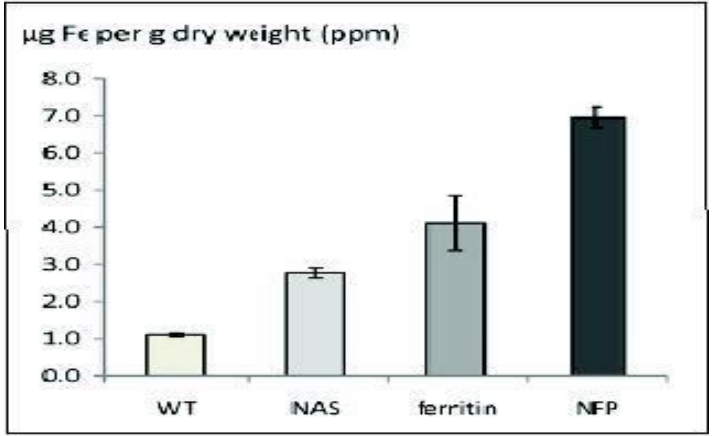

Fig. 3. Iron concentration in endosperm

Note: Fig. 2. Concentration of iron in leaves of wild type (WT) and NEP rice as a function of external iron concentration (J ohnathan Napier et al., 2010)

Fig. 3. Concentration of iron in polished grains of wild type (WT), NAS, Ferritin, and NEP rice on 200 micro meteriron supplied in the medium (J ohnathan Napier et al., 2010).

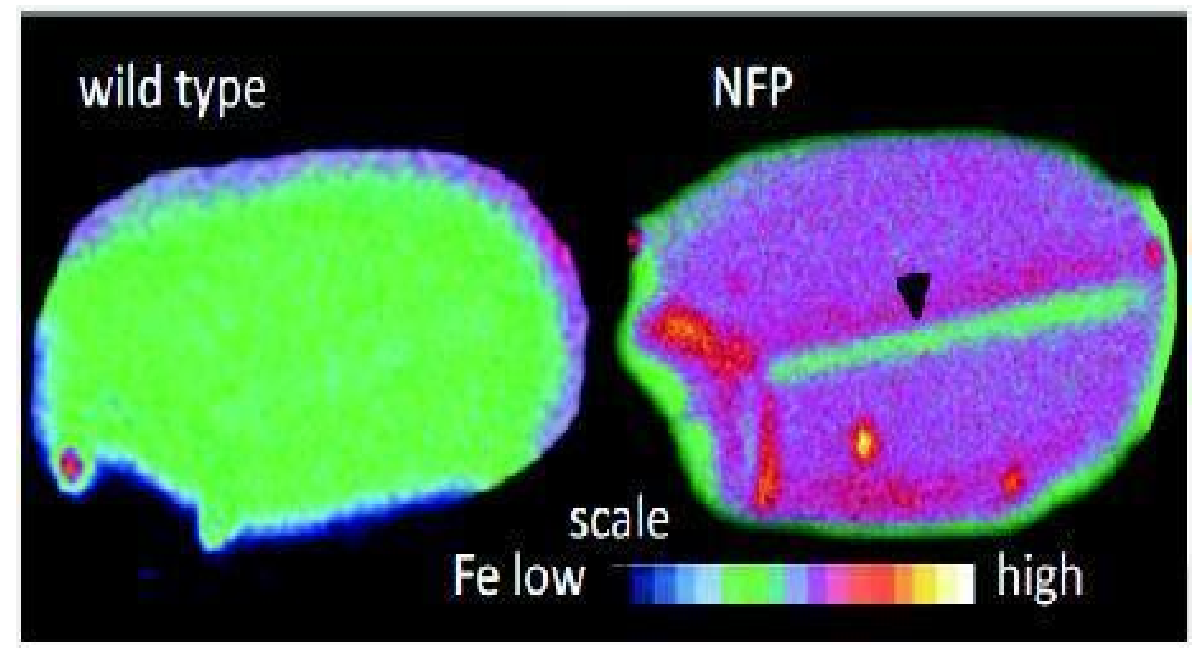

Fig. 4. Iron localization in endosperm grains ${ }^{-1}$ (Wild type vs NEP line)

Note: Fig 4. Element-sensitive mapping of iron concentration in a representative WT and NEP grain, acquired using micro-X-ray fluorescence spectrometry. The color indicates iron concentration. The low iron in NEP line representation the laser ablation track, which is out of focus and therefore iron concentration appears to be reduced along this line (arrowhead).

\section{Introducing $\beta$-carotene into the rice endosperm: (Golden rice)}

Introducing $\beta$-carotene into rice was developed about 20 years ago. Orange in color, it was genetically engineered to be rich in beta carotene, a nutrient that our body can easily converts its into Vitamin A. Scientists hoped that beta carotene containing rice would save lives and the eyesight of a quarter of a billion kids worldwide not getting enough vitamin A in their diets, children who typically live in less developed countries where ordinary rice is a dietary staple. The breakthrough of the so-called 'golden rice' made apparent that it was possible to engineer not only single proteins but to redirect a complete pathway with several involved enzymatic functions with no apparent pleiotropic effect. German professors Ingo Potrykus and Peter Beyer invented the 'golden rice' by genetic engineering at Switzerland's Federal Institute of Technology for the poor in developing countries with public money.

Early critiques of this transgenic biofortification were disappointed that 'golden rice' contained only low amounts of $\beta$-carotene and that it was a Japonica variety, which is not eaten in the areas of the most spread provitamin A deficiency. Meanwhile, this provitamin A biofortification has been transformed also into Indica rice lines (Datta et al., 2003), the varieties widely consumed in Asia. Indica varieties IR64 and MTL250 were obtained (Hoa et al., 2003) avoiding the antibiotic selection system, using a positive selection strategy (Lucca et al., 2001). The polished indica rice seeds contained lower level of $\beta$-carotene compared with the previous Japonica rice variety (Ye et al., 2000). 


\section{Gene source}

Golden rice (Vitamin A) is an example of a GM crop developed for its nutritional value. Golden rice contains PSY gene from daffodil and the CRTI gene from the bacterium Erwinia uredovora, both expressed only in the rice endosperm (Ye et al., 2000). Replacing PSY with genes from maize and rice increased the level of $\beta$-carotene by 23 times in Golden Rice (Paine et al., 2005) which can be converted by the body into vitamin A. This can help alleviate symptoms of vitamin A deficiency.

Notwithstanding the fact that rice plants synthesise $\beta$-carotene in vegetative tissues, located only in the outer cell layers of its seeds but not in the grain, which, however, are removed before storage by polishing. Processed rice is therefore full free of provitamin A.
$\beta$-Carotene synthesis in the endosperm of rice grains requires phytoene synthase to produce the intermediate phytoene from geranylgeranyl diphosphate (GGPP). Synthesis of $\beta$-carotene from phytoene needs three more plant enzymatic steps: phytoene desaturase (PDS), $\zeta$-carotene desaturase (ZDS) and lycopene $\beta$-cyclase. The Erwinia uredovora enzyme is able to perform the functions of both desaturases (for an overview of the pathway and the enzymes involved, (Burkhardt et al., 1997). A first step towards the production of $\beta$-carotene in staple crops has been reported in rice with the constitutive and endosperm-specific expression of a recombinant daffodil phytoene synthases cDNA (Burkhardt et al., 1997). The transgene driven by the constitutive promoter CaMV 35S produced a high infertility rate of the transgenic plants.

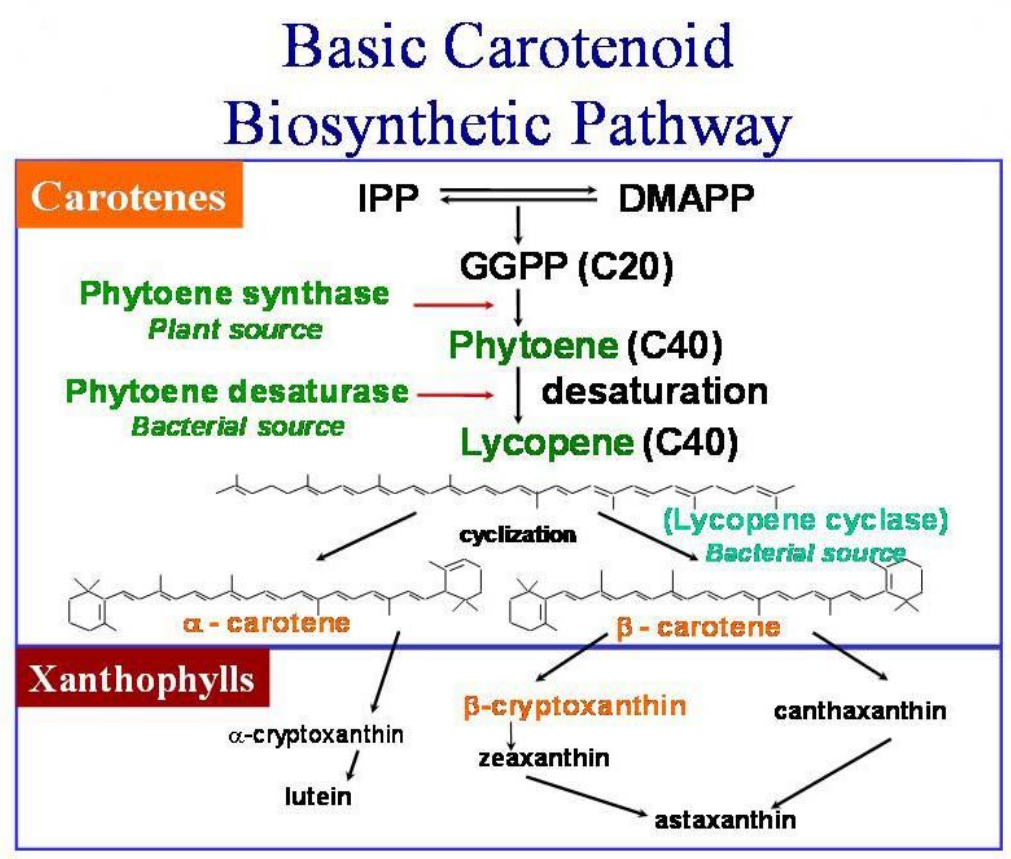

Fig. 5. Caroteniod synthesis

> To obtain the complete provitamin A biosynthetic pathway only in rice endosperm, Ye et al. (2000) have introduced the genes encoding the three enzymes, necessary to synthesize $\beta$-carotene form GGPP, into Japonica rice variety. Phytoene synthase (PSY) gene from daffodil and the phytoene desaturase (CRTI) gene from the bacterium Erwinia uredovora, both expressed only in the rice endosperms.

> A systematic test with psy cDNAs from alternative plant sources particularly rich in carotenoids indicated that the best strategy was probably to use the phytoene synthase (psy) from maize (Paine et al., 2005) instead of that from daffodil.
The combination of this psy cDNA with the Erwinia uredovora carotene desaturase under the control of an endosperm-specific promoter produced transgenic rice seeds with approximately 23-fold higher provitamin A content than the original J aponica golden rice variety.

$>$ Transformation of tobacco (Nicotiana tabacum) BY2 cells and Arabidopsis (Arabidopsis thaliana) plants is performed using the binary vector pSToff containing CRTI under the control of the constitutive CaMV 35S promoter, and PSY under the control of Gt1 promoter and hpt marker gene. 
$>$ The resulting vector is then transformed into the Agrobacterium tumefaciens strain GV3101.

$>$ After that this Agrobacterium tumefaciens when infect the target rice plant its modified T-DNA is introduced into the rice genome, and the rice plant get the desire gene and to accumulate the $\beta$-carotene inside the rice endosperm.
This new development is an exciting advance, and a further support that golden rice could complement existing efforts to end blindness and other diseases caused by vitamin A deficiency. The golden rice obtained from these will allow extended human nutritional work for investigation on bioavailability and carotenoid stability in rice food preparation with various forms of processing, storage and cooking.

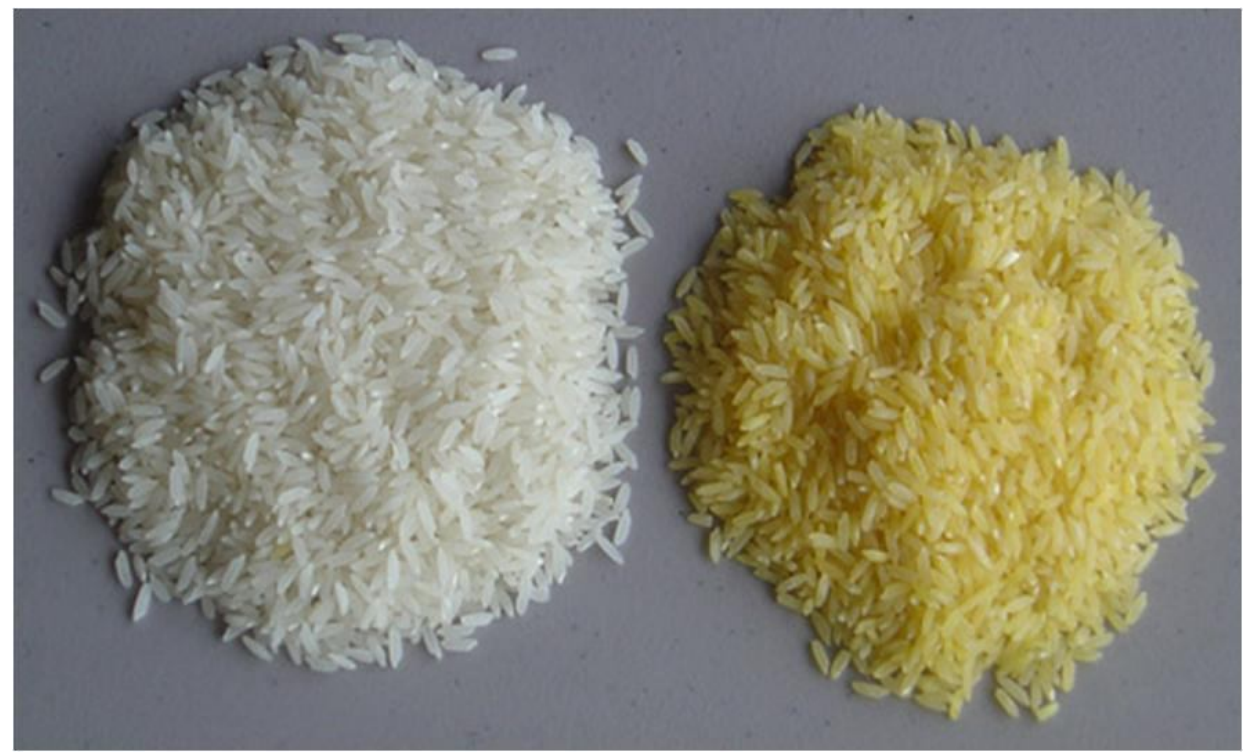

Fig. 6. $\beta$-carotene containing rice (yellow color) Vs normal rice (white color)

\section{Conclusion}

Biotechnology can help to address many challenges in the developing world but the political issue is always facilities this work to weak all over the world. The real challenges to solve micronutrient malnutrition diseases in the developing countries as well as are reduction of poverty and diseases and the increase of infrastructure and education system. All these issues are important and should continue to be addressed, as they have been in the past. In developing countries, rice biofortification is increasingly recognized as an effective approach to improve the micronutrient status of large parts of the populations like India, Myanmar, and Indonesia etc. improving nutritional quality of rice grains through genetic modification in the rice genome. Therefore, even a small improvement in nutritional content of rice seeds can have a dramatic impact on human health especially to the rural poor.

So, the review suggested that genetic engineering can be used as a promising approach for the biofortification of important staple crops focus to rice to address micronutrient deficiencies and improve human health.

\section{Future Prospect}

Bangladesh is an agriculture based developing country. It has a huge population, among them most of living under poverty and being suffered from basic nutrient in their diet.

Biofortification in rice is a relatively new field, while increasing essential micronutrients is our goal. Using this technique (genetic engineering) we would like to produce GM rice by introducing the folic acid biosynthesis gene into the rice plant. Folate is a $\beta$-group vitamin, also called folacin, critical for normal cellular function, insufficient intake causes megaloblastic anemia and there are strong linkages to cardiovascular diseases, various cancers and cognitive decline. It is also vital raw materials for red blood cell production in the blood and also has brain function.

Folic acid can be found in the leafy green vegetable, yeast, mushrooms, papaya etc. After over expressing two Arabidopsis thaliana genes of the pterin and para-aminobenzoate branches of the folate biosynthetic pathway from a single locus into the rice genome then, when the people eat the GM rice they will meet the sufficient folic acid that is crucial for the preventing the above diseases. 
If Bangladesh would approve folate enriched rice as in the future, several policy issues should be addressed, such as labeling, intellectual property rights and trade or price policy issues. Furthermore, the implementation of folate biofortification programs should initially reach its target group, women of childbearing age from poor, rural areas. Also the procedures to commercialize the rice and distribute the seeds (through farmers or other channels; voluntary or mandatory) should be clarified and supported. And even if the Bangladeshi policy would accept the production of biofortified staple crops, it should be taken into account that biofortification alone will only alleviate micronutrient malnutrition. A combination of interventions will be probably the most feasible and effective strategy to combat folate deficiency.

\section{Acknowledgements}

The authors express their sincere gratitude to Prof. Dr. Md. Shahidul Haque, Dept. of Biotechnology, Bangladesh Agricultural Univerity for their critically going through the manuscript. Special thanks due to Md. Abdul Khaleque, Israt Nadia, Tanusree Dey, Hriday Banik and Rifat Sultana for their valuable help in the preparation of the manuscript.

\section{References}

Anonymous. 2007. Global childhood malnutrition. The Lancet. 367: 1459.

Anonymous. 2008. The Copenhagen Consensus 2008 - Results. The Copenhagen Consensus Center, 1-6. (http:// www.copenhagenconsensus.com)

Behrman, J., Alderman, H., and Hoddinott, J. 2004. Hunger and malnutrition (Copenhagen Consensus Challenge Paper). Copenhagen, Denmark: Author. Bishai, D., \& Nilubola, R. 2002. The history of food fortification in the United States: Its relevance for current fortification efforts in developing countries. Economic Development and Cultural Change. 51 (1): 37-53.

Black, R.E., Allen, L.H., Bhutta, ZA., Caulfield, L.E., De Onis, M., Ezzati, M., Mathers, C. and Rivera, J. 2008. Maternal and child under nutrition: global and regional exposure and health consequences. Lancet. 371: 243- 260.

Burkhardt, P.K., Beyer, P., Wu"nn, J., Kloeti, A., Armstrong, G.A., Schledz, M., V. Lintig, J, and Potrykus, I. 1997. Transgenic rice (Oryza sativa) endosperm expressing daffodil (Narcissus pseudonarcissus) phytoene synthase accumulates phytoene, a key intermediate of provitamin A biosynthesis. Plant J ournal. 11: 1071- 1078.

CIAT/IFPRI. 2002. (International Center for Tropical Agriculture/International Food
Policy Research Institute). Biofortified crops for improved human nutrition. Program proposal. PP. III

Dallman, P.R.S.I., Imes, M.A. and Stekel, A. 1980. Iron deficiency in infancy and childhood. American J. Clin. Nutr. 33: 86118.

Datta, K., Baisakh, N., Oliva, N., Torrizo, L., Abrigo, E., Tan, J., Rai, M., Rehana, S., AlBabili, S., Beyer, P. Potrykus, I., Datta S.K. 2003. Bioengineered "golden" indica rice cultivars with b-carotene metabolism in the endosperm with hygromycin and mannose selection systems. Plant Biotechnol J. 1: 8190.

De Steur, H., X. Gellynck, S. Storozhenko, G. Liqun, W. Lambert, D. Van Der Straeten, J. Viaene. 2010. Willingness-to-Accept and Purchase Genetically Modified Rice With High Folate Content in Shanxi Province, China. 54: 118-125.

Drakakaki, G., Christou, P.and Stoger, E. 2000. Constitutive expression of soybean ferritin cDNA in transgenic wheat and rice results in increased iron levels in vegetative tissues but not in seeds. Transgenic Res. 9: 445452.

FAO. 1997. Preventing micronutrient malnutrition: a guide to food-based approaches. Why policy makers should give priority to food-based strategies.

Goto, F., Yoshihara, T. and Saiki, H. 1998. Iron accumulation in tobacco plants expressing soyabean ferritin gene. Transgenic Res. 7: 173- 180.

Goto, F., Yoshihara, T., Shigemoto, N., Toki, S. and Takaiwa, F. 1999. Iron fortification of rice seed by the soybean ferritin gene. Nature Biotechnol. 17: 282- 286.

Goto, F., Yoshihara, T. and Saiki, H. 2000. Iron accumulation and enhanced growth in transgenic lettuce plants expressing the iron-binding protein ferritin. Theor. Appl. Genet. 100: 658- 664.

Higuchi, K., Watanabe, S., Takahashi, M., Kawasaki, S., Nakanishi, H., Nishizawa, N.K., and Mori, S. 2001. Nicotianamine synthase gene expression differs in barley and rice under Fe-deficient conditions. Plant J. 25: 159- 167.

Hoa, T.T., Al-Babili, S., Schaub, P., Potrykus, I. and Beyer, P. 2003. Golden Indica and Japonica rice lines amenable to deregulation. Plant Physiol. 133: 161- 169.

http:/ / www.indexmundi.com/ bangladesh/popul ation_below_poverty_line.html

Johnathan Napier, Noemi Ruiz-Lopez, Tianbi Li, Richard Haslam and Olga Sayanova. 2010. The accumulation of novel omega-3 fatty acid in transgenic plants. ISB News Report. pp.1-3 
Kennedy, G., Nantel, G. and Shetty, P. 2003. The scourge of "hidden hunger": global dimensions of micronnutrient deficiencies. Food Nutr. Agr. 32: 8-16.

Lobreaux, S., Yewdall, S.J., Briat, J.F. and Harrison, P.M. 1992. Amino-acid sequence and predicted three-dimensional structure of pea seed (Pisum sativum) ferritin. Biochem J. 288 (3): 931- 939.

Lucca, P., Hurrell, R. and Potrykus, I. 2001. Genetic engineering approaches to improve the bioavailability and the level of iron in rice grains. Theor. Appl. Genet. 102: 392- 397.

Meng, F., Wei, Y. and Yang, X. 2005. Iron content and bioavailability in rice. J. Trace Element Med. Biol. 18: 333- 338.

Milman, N. and Kirchhoff, M. 1992. Iron stores in 1359, 30- to 60 years old Danish women: evaluation by serum ferritin and haemoglobin. Ann Hematol. 64: 22- 27.

Murray-Kolb, L.E., Welch, R., Theil, E.C. and Beard, J.L. 2003. Women with low iron stores absorb iron from soybeans. American J. Clin. Nutr. 77: 180- 184.

Paine, J.A., Shipton, C.A., Chaggar, S., Howells, R.M., Kennedy, M.J., Vernon, G., Wright, S.Y., Hinchliffe, E., Adams, J.L., Silverstone, A.L. and Drake, R. 2005. Improving the nutritional value of golden rice through increased pro-vitamin A content. Nature Biotechnol. 23: 482-487.

Qu, L.Q., Yoshihara, T., Ooyama, A., Goto, F. and Takaiwa, F. 2005. Iron accumulation does not parallel the high expression level of ferritin in transgenic rice seeds. Planta, (doi: 10.1007/s00425-005-1530-8), available at http:/ / www.springerlink.com/ media/3DGH VGQWVQW6D4V5PN5U/Contributions/ G/ 1 /4/X/G14X2411H716P336_html/fulltext.ht $\mathrm{ml}$.

Shekar, M., Heaver, R. and Lee, Y. (Eds.). 2006. Repositioning nutrition as central to development: A strategy for large scale action (Directions in Development Series). Washington, DC: World Bank.

Seymour, J.T. and Klein, T. 1996. Hungry for a new revolution. New Scientist. pp. 34- 37

Sobal, J., Khan, L.K. and Bisogni, C. 1998. A conceptual model of the food and nutrition system. Soc. Sci. Med. 47: 853-863.

Sommer, A. 1988. Avoidable blindness. Aust. N Z J. Ophthalmol. 16: 31- 35.

Storozhenko, S., De Brouwer, V., Volckaert, M., Navarrete, O., Blancquaert, D., Zhang, G.F., Lambert, W. and Van der Straeten, D. 2007. Folate fortification of rice by metabolic engineering. Nature Biotechnol. 25: 12771279.

UN/SCN (United Nations Systems Standing Committee on Nutrition). 2004. 5th report on world nutrition situation: Nutrition for improved development outcomes. Geneva, Switzerland. pp. 27-30.

UNICEF/MI. 2004. Vitamin \& Mineral Deficiencey. A Global Progress Report. Micronutrient Initative; Ottawa, Canada [http:// www.micronutrient.org/ reports/ ]

Welch, R.M. 2001. Micronutrients, agriculture and nutrition; linkages for improved health and well being. In: Perspectives on the Micronutrient Nutrition of Crops. Singh K, Mori S, Welch RM eds. Jodhpur, India: Scientific Publishers. pp. 247-289.

Welch, R.M. and Graham, R.D. 1999. A new paradigm for world agriculture: meeting human needs - Productive, sustainable, nutritious. Field Crops Res. 60: 1-10.

Welch, R.M. and Graham, R.D. 2000. A new paradigm for world agriculture: productive, sustainable, nutritious, healthful food systems. Food Nutr. Bull. 21: 361-366.

Welch, R.M. and Graham, R.D. 2004. Breeding for micronutrients in staple food crop from human nutrition perspective. J. Exp. Bot. 55: 353-364.

WHO (World Health Organization). 2002. The World Health Report 2002, Geneva.PP.8-10

WHO (World Health Organization). 2004. Iodine status worldwide: WHO global database on iodine deficiency. Geneva, Switzerland. p. 2

WHO and FAO. 2003. Diet, nutrition and the prevention of chronic diseases. Report of a joint WHO/ FAO expert consultation. WHO Technical Report Series 916.

WHO, World Food Programme \& UNICEF. 2007. Preventing and controlling micronutrient deficiencies in populations affected by an emergency. Geneva, Switzerland: WHO. From http://www. who. int/nutrition/publications/WHO_WFP_U NICEFstatement.pdf. p. 1

World Bank. 2007. From agriculture to nutrition: pathways, synergies and outcomes. Report 40196-GLB. Washington, D.C.: The International Bank for Reconstruction and Development / The World Bank. pp. 1-83.

Ye, X., Al-Babili, S., Kloti, A., Zhang, J., Lucca, P., Beyer, P. and Potrykus, I. 2000. Engineering the provitamin A (betacarotene) biosynthetic pathway and (carotenoid free) rice endosperm. Science. 287: 303-305. 